\title{
Do Gamma knife and cautery have a place in obesity treatment in future?
}

\author{
Suna Aydin ${ }^{1,2}$, Kader Ugur ${ }^{3}$ and Suleyman Aydin ${ }^{4 *}$ \\ ${ }^{1}$ Cardiovascular Surgery Department, Elazig Education and Research Hospital, Health Science University, Elazig, Turkey \\ ${ }^{2}$ Department of Anatomy, Medical School, Firat University, 23119 Elazig, Turkey \\ ${ }^{3}$ Department of Internal Medicine, Medical School, Firat University, 23119 Elazig, Turkey \\ ${ }^{4}$ Department of Medical Biochemistry and Clinical Biochemistry, (Firat Hormones Research Group), Medical School, Firat University, 23119 Elazig, Turkey
}

\begin{abstract}
Obesity is increasing day by day throughout the world. Nodaway's obesity surgery has been mostly performed for the treatment of obesity. However, many surgeons may be unsure for these advanced therapies because of stomach reduced irreversibly. Therefore, the aim of this work was to propose two novel methods (gamma knife or cautery) to destroy the stomach cells that produce ghrelin, (cells that have been postulated have an important role in the origin of appetite in humans). That's this paper postulate that, the appetite of an individual shall decrease as the cells releasing the appetite hormone for the method recommended herein, and a limitation shall occur in the eating and the weight losses shall happen. We also present some images of the coordinates of the stomachs, highlighting the anatomical origin produced by the appetite hormone and the obesity. Furthermore, we described images the procedure of cauterization and the use gamma knife of the anatomical region of the stomach producing ghrelin, as well as the layers of the stomach that would be altered with the procedure. Eventually we foresee that gamma knife or cautery might be alternative options for solving the obesity problem in the future.
\end{abstract}

\section{Introduction}

Obesity is an important public health problem in the global extent, which has been since the beginning of humanity (it should be remembered that the genetic material DNA does never forget the information it carries) and of which prevalence had increased being become prevalent of the modern life style [1]. In accordance with the study of NHANES (USA-National Health and Nutrition Examination Survey) performed by the Centers for Disease Control and Prevention $(\mathrm{CDC})$ in USA, the obesity (Body Mass Index - MBI > 30) prevalence had been stated that it was $39.8 \%$ among U.S. adults in 2015-2016 [2]. In Europe, the obesity prevalence varies between $32-79 \%$ in the males and $28-78 \%$ in the females taking in to account the adults [3]. Moreover, in MONICA study, which had been performed by World Health Organization in 6 different regions of Asia, Africa and Europe and continued for 12 years, it had been reported that there was an increase between $10-30 \%$ for the obesity prevalence in 10 years [4].

Even though the genetical, environmental, neurological, physiological, biochemical, socio-cultural and psychological factors had been asserted as the underlying main reasons of the obesity; the main reason results from the over food consumption, malnutrition and physical activity insufficiency [1]. As a result of all these factors, there is an abnormal steatopygia in the body, and this abnormal steatopygia reduces the human beings' life quality and shortens the life by forming a basis to many important disorders such as the respiratory system (sleep apnea), cardiovascular system (hypertension), hormonal system (insulin resistance), digestive system, depression, impotency and paralysis [1,3].

As the human beings undoubtedly make a success of everything, the obesity also makes a success of the applications such as gastric balloon application, 'gastric bypass'; sleeve gastrectomy and obesity surgery" or "bariatric surgery. These surgical operations made to the digestive systems reduce the food intake or food absorption or both of them and therefore, it causes to the weight losses in the individuals [5].

The important developments are progressed in the obesity surgery field in conjunction with the development of technology. The patients heal in a short span of time after the closed (laparoscopic) method obesity surgeries, and they may easily come back to their daily lives. We should not forget that the same intervention is not applied for every patient in the bariatric surgery, and there is not an approach such as it is "only and better method" $[5,6]$. The obesity surgery, or more widely known as sleeve gastrectomy surgery, results in bringing the stomach to the tube formation by taking the part producing the appetite hormone (ghrelin cells) in the fundus region of the stomach. Therefore, as the appetite is repressed, the over food consumption is also prevented [7].

However, the main problem in the sleeve gastrectomy surgery is that it is not possible for an excised biological organ (excluding the liver organ) to change back into the previous situation. Therefore, it is more reasonable to find a remedy to the obesity without losing any part of the organ. This situation may be got through the cauterization [8]. That is to say that the stomach's part releasing the appetite hormone may be destroyed by using the endoscopic method and burning with the cautery

${ }^{\star}$ Correspondence to: Suleyman Aydin, Department of Medical Biochemistry and Clinical Biochemistry, (Firat Hormones Research Group), Medical School, Firat University, 23119 Elazig. Turkey, Tel: +90 5334934643; Fax: +90 424 2379138; E-mail: saydin1@hotmail.com

Key words: gamma knife, obesity, gastrectomy surgery, ghrelin, stereotactic radiosurgery

Received: May 01, 2018; Accepted: May 15, 2018; Published: May 21, 2018 
(Figure 1). The appetite of an individual shall decrease as the cells releasing the appetite hormone for the method recommended herein (Figure 1), and a limitation shall occur in the eating and the weight losses shall happen. The burned ulcers to be occurred depending on the cautery may also disappear in a time period such as approximately 2 months [9]. In cases where the intended weight may not be reached in this two-month period, the target may be focused by repeating it in the certain periods.

Moreover, the Gamma knife (stereotactic radiosurgery) technique [10] may also be used to eliminate the obesity surgeries. In other words, upon determining the coordinates of the stomach's part producing the appetite hormone and the obesity may be brought under control without reducing the stomach by removing these parts with the Gamma knife (Figure 2).

In the future, we may move ahead of the obesity being a serious public health all over the world by removing the irreversible losses of the

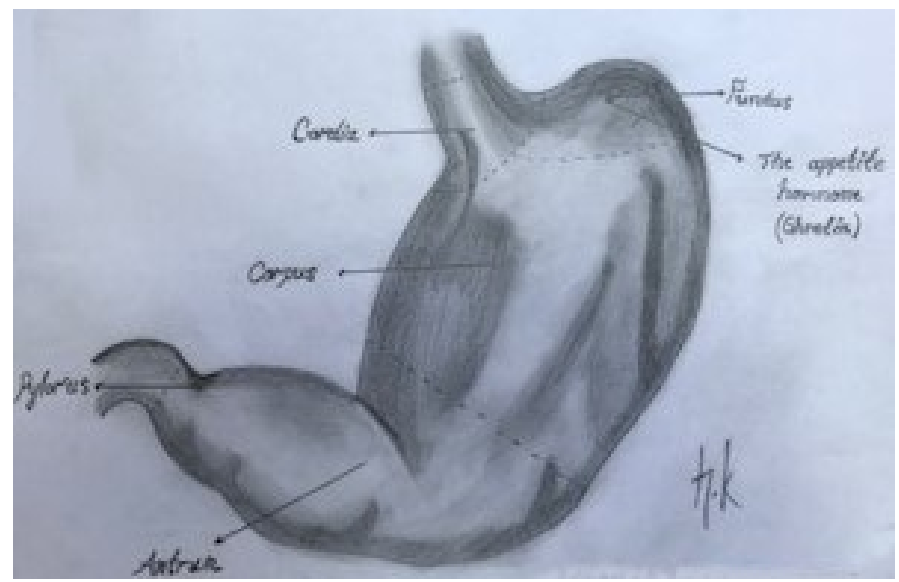

Figure 1. Images of the coordinates of the stomach's, Fundus is the anatomical origin that produced the appetite hormone

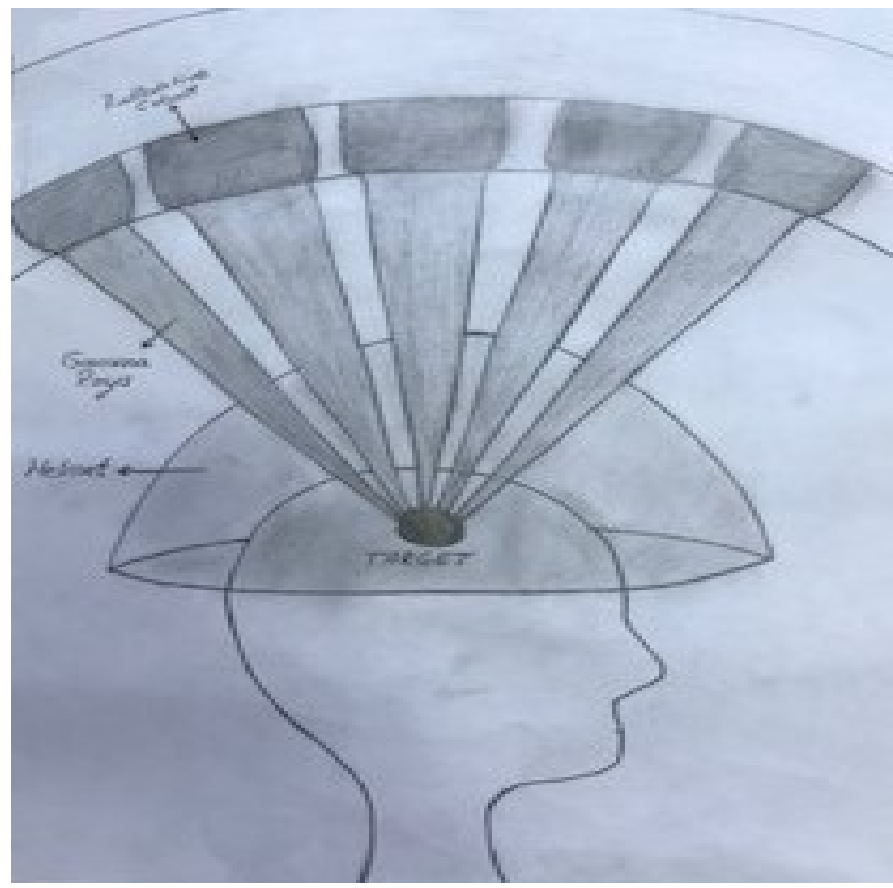

Figure 2. A presentative image of the Gamma knife: Gamma knife can be used to eliminate the appetite hormone producing cells in the fundus part of stomach as shown in the Figure 1 stomach with these methods propounded herein [11]. We predict that being as immediate as possible tested of the hypotheses propounded herein with the animal experiments shall be able to be an important step for the mankind. It is also predicted that they shall be able to be form important basis for the solution-oriented steps by revealing whether or not the burned ulcers occurred depending on the cauterization to transform into the cancer at the end of the experiments. It is surely beyond doubt that the appetite does not only depend on the ghrelin released by the ghrelin cells in the stomach. It depends on the great numbers of appetizing and non-appetizing molecules released from the central nervous system. These methods predicted for the stomach may preclude the obesity by means of using to control the appetite center in the brain one day in the future, and the brain surgeons may also step in order to provide the control of the obesity in addition to the general surgery one day in the future.

\section{Acknowledgments}

We would like to extend our sincerest thanks to our former trainee Hacer Karabektas, M.D. who produced charcoal drawings of the figures.

\section{References}

1. Ugur K, Sahin I, Aydin S (2017) Biochemistry of Obesity and Its World-Wide Prevalence. Adv Biochem Biotehcnol 6: 1-5.

2. https://www.cdc.gov/nchs/data/factsheets/factsheet_nhanes.htm

3. Bagriacik N, Onat H, Ilhan B, Tarakci T, Osar Z, et al. (2009) Obesity profile in Turkey. Int J Diabetes Metab 17: 5-8.

4. http://www.beslenme.saglik.gov.tr/index.php?lang=tr\&page=39

5. Kim SH, Chun HJ, Choi HS, Kim ES, Keum B, et al. (2016) Current status of intragastric balloon for obesity treatment. World $J$ Gastroenterol 22: 5495-5504. [Crossref]

6. Guan B, Yang J, Chen Y, Yang W, Wang C (2018) Nutritional Deficiencies in Chinese Patients Undergoing Gastric Bypass and Sleeve Gastrectomy: Prevalence and Predictors. Obes Surg. [Crossref]

7. Zhao Z, Sakai $T$ (2008) Characteristic features of ghrelin cells in the gastrointestinal tract and the regulation of stomach ghrelin expression and production. World $J$ Gastroenterol 14: 6306-6311. [Crossref]

8. McCullagh KG, Silver IA (1981) The actual cautery -- myth and reality in the art of firing. Equine Vet $J$ 13: 81-84. [Crossref]

9. Sabzi F, Faraji R (2014) Factors predicts skin ulcer following coronary artery bypass $J$ Med Life 2: 29-33. [Crossref]

10. Nwokedi EC, DiBiase SJ, Jabbour S, Herman J, Amin P, et al. (2002) Gamma knife stereotactic radiosurgery for patients with glioblastoma multiforme. Neurosurgery 50 : 41-46. [Crossref]

11. Aydin S, Ugur K, Yardim M (2017) Is Control of Obesity Hidden in Catecholamine Metabolizing Enzyme Renalase? J Clin Nutr Diet 3: 26.

Copyright: (C2018 Aydin S. This is an open-access article distributed under the terms of the Creative Commons Attribution License, which permits unrestricted use, distribution, and reproduction in any medium, provided the original author and source are credited. 